EPiC Series in Engineering
Volume 3, 2018, Pages 967-974
HIC 2018. 13th International
Conference on Hydroinformatics

\title{
Seasonal and Spatial Variation of Seismic Activity due to Groundwater Fluctuation in South Korea
}

\author{
Suk Hwan Jang ${ }^{1 *}$, Kyoung Doo $\mathrm{Oh}^{2 \dagger}$, Jae Kyoung Lee ${ }^{1 \ddagger}$ and Jun Won Jo ${ }^{1 \S}$ \\ ${ }^{1}$ Daejin Univiersity, Gyeonggi-do, Republic of Korea \\ ${ }^{2}$ Korea Military Academy, Seoul, Republic of Korea \\ okd0629@hanmail.net, prjang@naver.com
}

\begin{abstract}
We hypothesized that groundwater flow could trigger earthquakes both in the land and in the sea due to its seasonal fluctuation following the wet season. Using 1,157 earthquake data recorded starting from 1978 to 2017 by Korea Meteorological Agency monthly earthquake energy and count of occurrence were analyzed to test the hypothesis. For the earthquakes occurred in the land a six-month earthquake active period from August to January was identified, which starts two months later from the beginning of the monsoon season (June-September). Meanwhile, for the earthquakes occurred in the sea another six-month earthquake active period from February to July, delayed by six months from that of the land, was also identified. These two-month and 8-month time lags between the active periods and the monsoon season seem to be attributable to the time required for groundwater to recharge aquifer, to propagate increased hydraulic pressure through fractures and to travel from the land to the sea. Monthly earthquake count and energy series seem to support the main shockaftershock relation proposed by the hydroseismicity model but with longer and more variable time lags (i.e. one month for the sea and three to five months for the land) than those suggested by the hydroseismicity model. An excellent correlation of earthquake energy series which means almost perfectly synchronized activation of earthquakes between the land and the South Sea having the shortest travel path with steep slope among three seas seems to be the strong evidence supporting the hydroseismicity of earthquakes occurring in South Korea. Considering constant movement of tectonic plates which builds up intraplate stress relentlessly the cyclic burst of earthquake energy release supposed to be triggered by groundwater fluctuation seems to be playing the role of invisible hands which prevent excessive accumulation of geotectonic energy in the curst. From this point of view ongoing climatic change that might bring about abnormal behavior of groundwater flow may change not only the pattern but also the magnitude of earthquakes occurring in South Korea in the future.
\end{abstract}

\footnotetext{
* Professor, Department of Construction System \& Environmental Engineering, Daejin University

${ }^{\dagger}$ Professor, Department of Civil Engineering \& Environmental Sciences, Korea Military Academy

* Professor, Industry-Academia Cooperation Group, Daejin University

${ }^{\S}$ Ph.D. student, Department of Civil Engineering, Daejin University
} 


\section{Introduction}

South Korea which is located in an intraplate seismic zone had long been believed to be the relatively safe place from earthquake threat. However, the recent earthquake of $\mathrm{M}_{\mathrm{L}} 5.8$ occurred in Gyeongju City on 12 September 2016 has changed this belief altogether. This research was also stemmed from this changed view on earthquake threat in South Korea.

As for the cause of the Gyeongju earthquake there has been no firm conclusion yet. Many research projects have been launched since this earthquake drew national concern about potential catastrophic earthquake hazard. Most of the researches have focused on faults, the traditional theme of this field.

However, our main theme of the research has been the relation between seismicity and hydrological cycle. Costain and Bollinger (2010) proposed that naturally occurring earthquakes anywhere on Earth belong to one of two types: (1) interplate seismicity associated with the dynamics of plate tectonics; and (2) intraplate seismicity associated with the dynamics of the hydrological cycle.

This paper introduced the hydroseismicity model proposed by Costain (2016) briefly and then explored possible evidence of the cause-and-effect relation between groundwater flow and seismicity using earthquake data recorded in South Korea.

\section{Materials and methods}

The hydroseismicity model explains intraplate earthquakes by a three-step process. (1) First, a prolonged period of relatively higher groundwater recharge (i.e. above-average recharge) builds up pore fluid pressure in a fractured self-organized critical (SOC) crust through the accumulation of Biot slow waves until a main shock is triggered. (2) Second, the main shock creates a network of new fractures in a high-strain weaker zone where was not sufficiently permeable before the main shock. (3) With increased crustal permeability in the newly fractured zone pore-fluid pressure transients created by the main shock trigger aftershocks.

Costain (2016) suggested that only 0.01 to $0.1 \mathrm{MPa}$ (about 1 to $10 \mathrm{~m}$ of hydraulic head) of porefluid overpressure is generally sufficient to trigger an intraplate earthquake in the SOC crust but persistence of pore-fluid overpressure is a key factor in triggering intraplate seismicity. And he also suggested that depending on the hydraulic diffusivity of the crust there were one- to six-month time lags between groundwater recharge and the onset of seismicity.

This paper explored plausible evidence of the hydroseismicity model using earthquake data recorded in South Korea. Figure 1 shows a catalogue of 1,157 earthquake magnitudes with minimum threshold of 2.0 recorded starting from 1978 to 2017 by Korea Meteorological Agency.

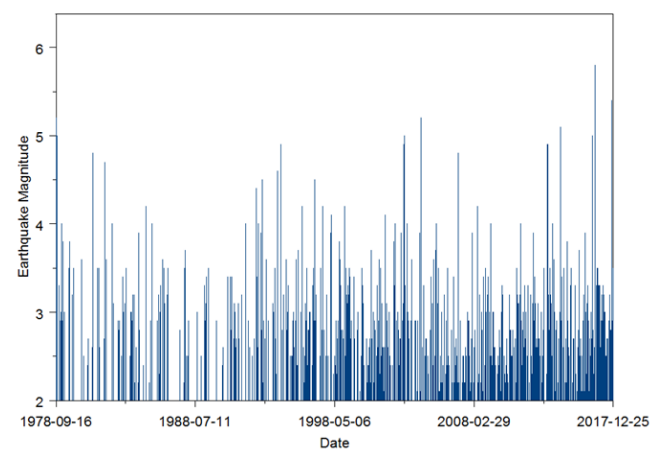

Figure 1: Earthquakes occurred in South Korea (data source: http://www.weather.go.kr/weather/earthquake volcano/domesticlist.jsp) 
Table 1 shows a summary statistics of the earthquake data shown in Figure 1.

\begin{tabular}{cccc}
\hline Statistics & Earthquake magnitude & Statistics & Earthquake magnitude \\
\hline Min. & 2.00 & Variance & 0.31 \\
1st Qu. & 2.30 & Std. Dev. & 0.56 \\
Mean & 2.67 & Skewness & 1.59 \\
Median & 2.50 & Kurtosis & 3.75 \\
3rd Qu. & 2.90 & Total N & 1,157 \\
Max. & 5.80 & & \\
\hline
\end{tabular}

Table 1: Statistics of earthquakes occurred in South Korea (1978-2017)

We first sorted out 1,157 earthquakes by the place where they occurred (i.e. 520 earthquakes in the land and 637 earthquakes in the sea). Next, we further sorted out these two groups of earthquakes by the month when they occurred. Then for each month we computed earthquake energy and count of occurrence to find any evidence that would support the hydroseismicity model with respect to seasonal and spatial variation of seismicity in relation with the monsoon season.

\section{Results and discussion}

\subsection{Earthquakes in the land}

Figure 2 shows two series of earthquake data (i.e. monthly count and energy of earthquakes) which occurred in the land from 1978 to 2017. In order to facilitate to grasp some patterns of these series that seem to expand over two years from August to July of the next year 12-month data series were repeated three times. Repeating data series was applied to other ones following this.

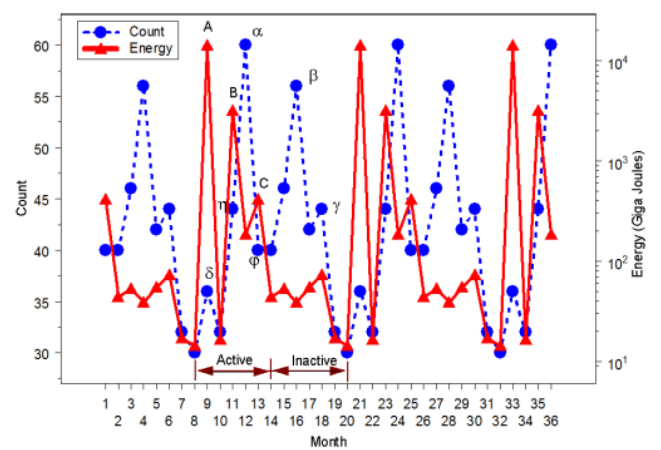

Figure 2: Monthly count and energy of earthquakes occurred in the land

As shown in Figure 2 we divided the 12-month energy series into two categories: an active period (August-January) and an inactive period (February-July). The active period starts two months later from the beginning of the monsoon season (June-September). For the active period, a cascade of high energy release peaking in September, November and January with descending energy level and bimonthly cycle seems to suggest that this is a typical energy release pattern for a dissipative dynamical system. In fact, the energy series of the whole year including the inactive period looks like a characteristic behavior of a dissipative system converting cumulated potential energy into heat. 
Though in Figure 2 visually the count and energy series show some similar patterns of variation (e.g. energy A matches with count $\alpha$, energy B matches with count $\beta$ and energy C matches count $\gamma$ ) a statistical test revealed virtually no interdependence between two series due to 3- to 5-month time lags between them. To perform a correlation analysis between the count and energy series the energy series was moved backward by 4 months (e.g. the energy of September moved to January of the next year as shown in Figure 3). Now two series show a relatively good correlation coefficient of 0.62 .

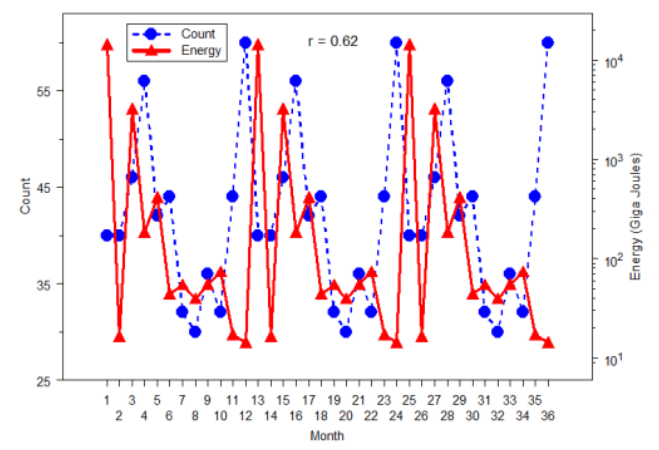

Figure 3: Monthly count and energy series after moving energy backward by 4 months

One possible explanation on this fairly good correlation between two series originally lagged by 3 to 5 months might be a main shock-aftershock relation as shown in Table 2. It is interesting that average energy of aftershocks is one or two orders of magnitude smaller than that of main shocks. And it is also noteworthy that count of main shocks $(\delta, \eta, \varphi)$ is lesser than that of aftershocks $(\alpha, \beta, \gamma)$.

\begin{tabular}{cccccccc}
\hline & \multicolumn{3}{c}{ Main shocks } & \multicolumn{4}{c}{ Aftershocks } \\
$\begin{array}{c}\text { Data } \\
\text { point }\end{array}$ & Count & $\begin{array}{c}\text { Total } \\
\text { energy } \\
(\mathrm{GJ})\end{array}$ & $\begin{array}{c}\text { Average } \\
\text { energy } \\
(\mathrm{GJ})\end{array}$ & $\begin{array}{c}\text { Data } \\
\text { point }\end{array}$ & Count & $\begin{array}{c}\text { Total } \\
\text { energy } \\
(\mathrm{GJ})\end{array}$ & $\begin{array}{c}\text { Average } \\
\text { energy } \\
(\mathrm{GJ})\end{array}$ \\
\hline A & 36 & 14,201 & 394.5 & $\alpha$ & 60 & 185 & 3.1 \\
B & 44 & 3,177 & 72.2 & $\beta$ & 56 & 39 & 0.7 \\
C & 40 & 413 & 10.3 & $\gamma$ & 44 & 73 & 1.7 \\
\hline
\end{tabular}

Table 2: Main shock-aftershock relation of the earthquakes occurred in the land

\subsection{Earthquakes in the sea}

Figure 4 shows two series of earthquake data (i.e. monthly count and energy of earthquakes) which occurred in the sea from 1978 to 2017. As the same way for the land 12-month data series were repeated three times to facilitate to find out some patterns of these series. Monthly count and energy series show a relatively good correlation coefficient of 0.58 even without time-shifting of any series. 


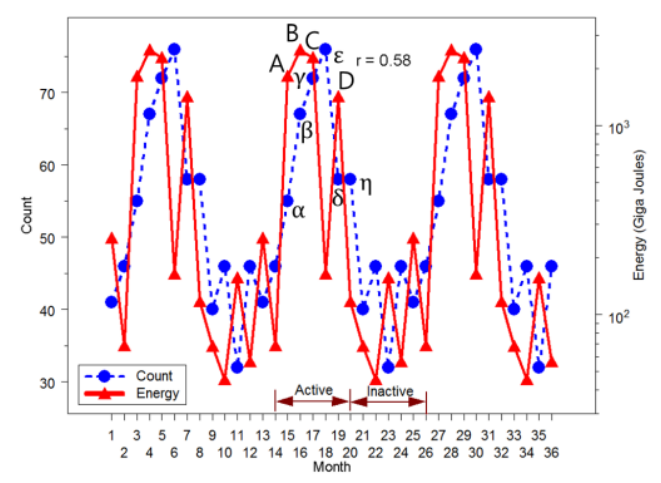

Figure 4: Monthly count and energy of earthquakes occurred in the sea

For the sea an active period (February-July) and an inactive period (August-January) are exact opposite for the land. The active period starts 8 months later from the beginning of the monsoon season (June-September). For the active period, a burst of high energy release (A, B, C) is concentrated from March to May and another smaller peak (D) occurs in July. In the active period there are only two months $(\varepsilon, \eta)$ being discernible as aftershocks. This pattern of energy release in the sea that needs only one-month lags for aftershock development after main shocks seems to be quite different from that of the land that requires 3- to 5-month lags for the same process. This might be an indication that the crust of the sea under enormous loading of seawater is in more critical state than the land assuming other conditions are the same including properties of rocks, yet which might not be quite true.

To get better matching between the count and energy series the energy series was moved backward by one month (e.g. the energy of April moved to May as shown in Figure 5). Now two series show a very good correlation coefficient of 0.87 .

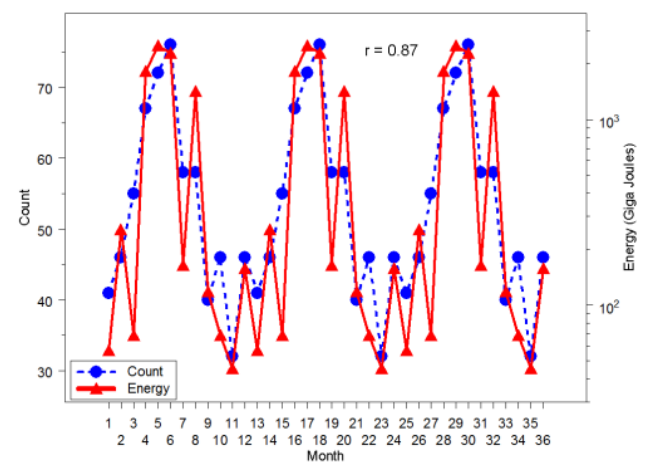

Figure 5: Monthly count and energy series after moving energy backward by one month

As the same way for the land monthly count and energy series of the sea were analyzed for the main shock-aftershock relation as shown in Table 3. It is noteworthy that average energy of aftershocks is one order of magnitude smaller than that of main shocks compared to one or two orders of magnitude difference for the land. Average energy of both main shocks (24.4-37.3 GJ) and aftershocks (2.0-2.2 GJ) for the sea is less variable compared to that of main shocks (10.3-394.5 GJ) and aftershocks (0.7-3.1 GJ) for the land. And it is also noteworthy that count of main shocks (C, D) is comparable with that of aftershocks $(\varepsilon, \eta)$ compared to larger count of aftershocks than that of main 
shocks for the land. All these things together seem to indicate consistently that fractures of the sea are probably more uniform in their structural properties like size and density than those of the land.

\begin{tabular}{cccccccc}
\hline \multicolumn{3}{c}{ Main shocks } & \multicolumn{5}{c}{ Aftershocks } \\
$\begin{array}{c}\text { Data } \\
\text { point }\end{array}$ & Count & $\begin{array}{c}\text { Total } \\
\text { energy } \\
(\mathrm{GJ})\end{array}$ & $\begin{array}{c}\text { Average } \\
\text { energy } \\
(\mathrm{GJ})\end{array}$ & $\begin{array}{c}\text { Data } \\
\text { point }\end{array}$ & Count & $\begin{array}{c}\text { Total } \\
\text { energy } \\
(\mathrm{GJ})\end{array}$ & $\begin{array}{c}\text { Average } \\
\text { energy } \\
(\mathrm{GJ})\end{array}$ \\
\hline A & 55 & 1,813 & 33.0 & & & & \\
B & 67 & 2,498 & 37.3 & & & & \\
C & 72 & 2,279 & 31.7 & $\varepsilon$ & 76 & 164 & 2.2 \\
D & 58 & 1,414 & 24.4 & $\eta$ & 58 & 117 & 2.0 \\
\hline
\end{tabular}

Table 3: Main shock-aftershock relation of the earthquakes occurred in the sea

\subsection{Comparison between the land and the sea}

To explore any clues to explain the difference in the patterns of energy release between the land and the sea monthly count and energy of the land and the sea were compared as shown in Figures 6 and 7 with some time-shifting for the land's series.

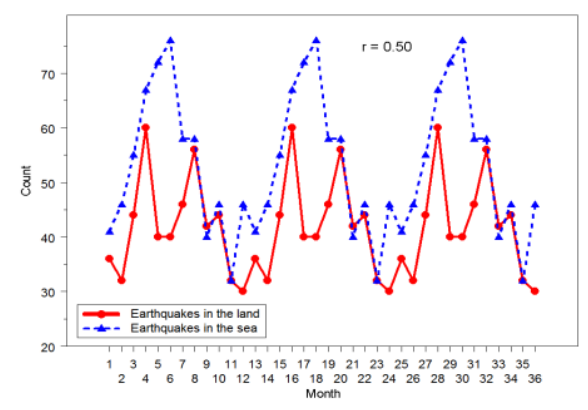

Figure 6: Monthly count series after moving the land's series backward by 4 months

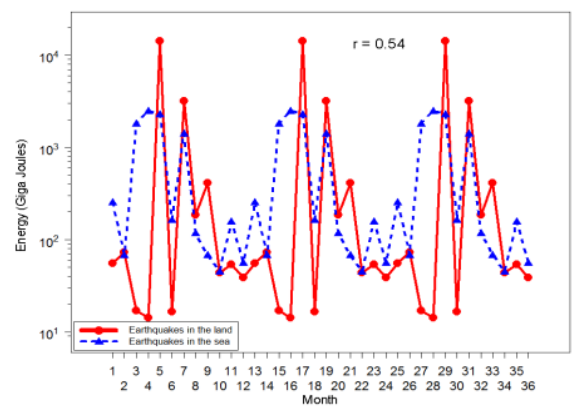

Figure 7: Monthly energy series after moving the

land's series backward by 8 months

As shown in Figures 6 and 7 there is discrepancy in the patterns of peaks for both the count and energy series between the land and the sea. While the land has only one peak month for its first peak the sea has three peak months in row for its first peak, which means the sea has two more peak months compared to the land. We suspected this might be due to the difference in travel time for groundwater flowing from the land to the sea because the sea comprises three smaller seas with different contributing watersheds as shown in Figure 8. 


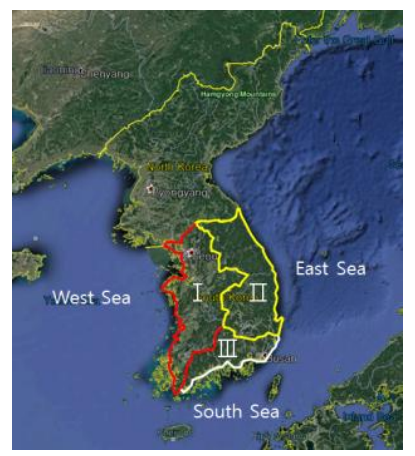

Figure 8: Three seas and their contributing watersheds (Satellite image from Google Earth)

Table 4 summarizes the characteristics of the contributing watersheds for three seas.

\begin{tabular}{|c|c|c|c|c|c|}
\hline \multirow{2}{*}{ Sea } & \multirow{2}{*}{ Watershed } & \multirow{2}{*}{$\begin{array}{l}\text { Area } \\
\left(\mathrm{km}^{2}\right)\end{array}$} & \multicolumn{2}{|c|}{ Travel distance $(\mathrm{km})$} & \multirow{2}{*}{$\begin{array}{l}\text { Average surface slope of } \\
\text { the longest travel path (\%) }\end{array}$} \\
\hline & & & Mean & Max. & \\
\hline West Sea & I & 39,600 & 97 & 228 & 0.27 \\
\hline East Sea & II & 36,900 & 119 & 153 & 0.29 \\
\hline South Sea & III & 15,100 & 57 & 91 & 0.68 \\
\hline
\end{tabular}

Table 4: Three seas and characteristics of their contributing watersheds

Figures 9 through 11 compare monthly energy series between these seas. The West Sea and the East Sea show the highest correlation coefficient of 0.54 while the East Sea and the South Sea show the lowest correlation coefficient of 0.19. For their first peaks the West Sea and the East Sea have 3month peak in common while the South Sea has a one-month peak. Both the one-month peak of the South Sea and 3-month peak of the West Sea and the East Sea have the first peak month on March in common. This seems to imply the same arrival time for groundwater coming from three watersheds. However, 3-month peak of the West Sea and the East Sea have two more peak months of April and May, which seems to be attributable to the presumed extended period of groundwater inflow into these two seas due to far longer travel distance from their contributing watersheds compared to the South Sea.

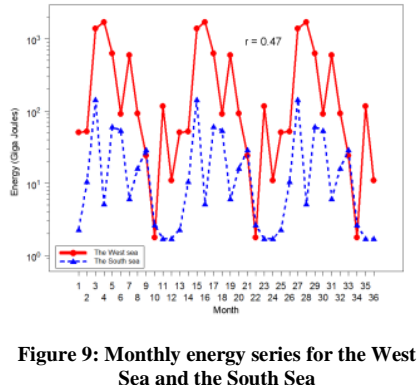

Sea and the South Sea

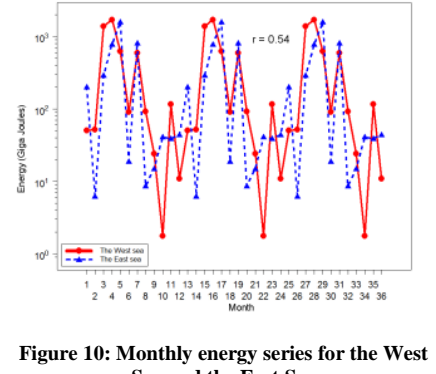

Sea and the East Sea

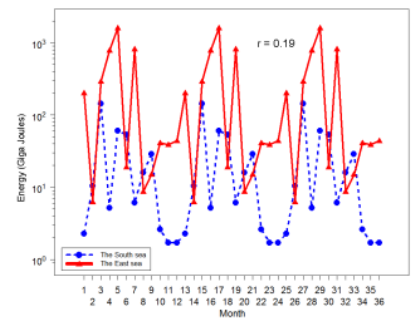

Figure 11: Monthly energy series for the East Sea and the South Sea

Figures 12 through 14 compare monthly energy series between the land and three seas. Monthly energy series of the land was moved backward by 6 months to compute correlation coefficients between the land and the seas. The land and the South Sea show the highest correlation coefficient of 
0.93 while the land and the East Sea show the lowest correlation coefficient of 0.19. This excellent correlation between the land and the South Sea seems to be attributable to the short travel path with steep slope for groundwater flow to reach the South Sea from its contributing watershed.

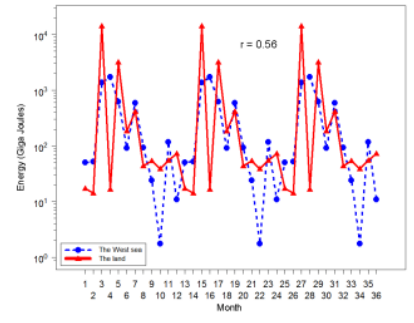
Figure 12: Monthly energy series for the West
Sea and the land

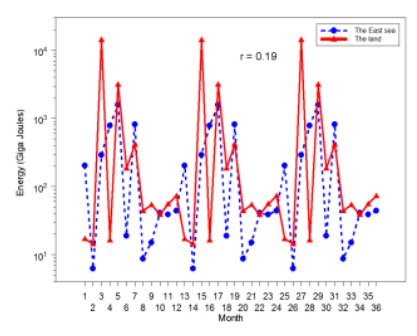

Figure 13: Monthly energy series for the East Sea and the land

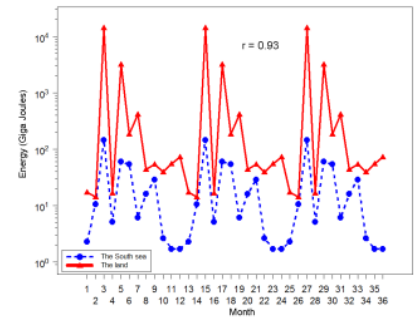
Figure 14: Monthly energy series for the South
Sea and the land

\section{Conclusion}

For the earthquakes analyzed in this study the active and inactive periods for the land and the sea in relation with the monsoon season were identified. There were two-month and 8-month time lags between the active periods for the land and the sea and the monsoon season and this seems to be attributable to the time required for groundwater to recharge aquifer, to propagate increased hydraulic pressure through fractures and to travel from the land to the sea. Monthly earthquake count and energy series seem to support the main shock-aftershock relation proposed by the hydroseismicity model but with longer and more variable time lags (i.e. one to five months) than those suggested by the hydroseismicity model. An excellent correlation of earthquake energy series between the land and the South Sea having the shortest travel path with steep slope seems to be the strong evidence supporting the hydroseismicity of earthquakes occurring in South Korea. The cyclic burst of earthquake energy release seems to prevent excessive accumulation of geotectonic energy in the curst. On-going climatic change that might bring about abnormal behavior of groundwater flow may change not only the pattern but also the magnitude of earthquakes occurring in South Korea in the future.

Acknowledgements: This work was supported by grant NFR-2017R1E1A1A01075118 through Basic Science Research Program of National Research Foundation of Korea (NRF).

\section{References}

Costain, J.K. and Bollinger, G.A. (2010). Review: research results in Hydroseismicity from 1987 to 2009. Bulletin of the Seismological Society America, 100, 18411858.

Costain, J.K. (2016). Groundwater recharge as the trigger of naturally occurring intraplate earthquakes. Landgraf, A., Kuebler, S., Hintersberger, E. and Stein, S. (eds) Seismicity, Fault Rupture and Earthquake Hazards in Slowly Deforming Regions. Geological Society, London, Special Publications, 432.

Korea Meteorological Agency. (n.d.). Retreived from http://www.weather.go.kr/weather/ earthquake volcano/domesticlist.jsp.

Suk Hwan Jang, Kyoung Doo Oh, Jae Kyoung Lee and Jun Won Jo. (2017). The draft report submitted to NRF for the $1^{\text {st }}$ year research work on hydroseiemicity in South Korea (in Korean). Daejin University. 